\title{
A Rare Case of Small Cell Lung Cancer With an Epidermal Growth Factor Receptor Mutation and Its Response to Osimertinib
}

\author{
Sakil Bhuiyan ${ }^{1}$, Raheel S. Siddiqui ${ }^{1}$, Milana Zirkiyeva ${ }^{1}$, Mariam Agladze ${ }^{1}$, Tayyaba Bashir ${ }^{2}$ \\ 1. Internal Medicine, Icahn School of Medicine at Mount Sinai, Queens Hospital Center, New York City, USA 2. \\ Hematology and Medical Oncology, Icahn School of Medicine at Mount Sinai, Queens Hospital Center, New York City, \\ USA \\ Corresponding author: Sakil Bhuiyan, sakilb1@gmail.com
}

\begin{abstract}
Small cell lung cancer (SCLC) accounts for less than $15 \%$ of the cases of lung cancer. Epidermal growth factor receptor (EGFR) mutations are rarely reported in association with SCLC. EGFR tyrosine kinase inhibitors (TKI) are approved as the first-line therapy for metastatic non-small cell lung cancer (NSCLC). The clinical effect of EGFR mutations and its response to osimertinib are unknown in SCLC. We report a case of EGFRpositive metastatic SCLC in a 63-year-old female who was treated with the third-generation TKI, osimertinib.
\end{abstract}

Review began 04/28/2021 Review ended 05/13/2021 Published 05/20/2021

(c) Copyright 2021 Bhuiyan et al. This is an open access article distributed under the terms of the Creative Commons Attribution License CC-BY 4.0, which permits unrestricted use, distribution, and reproduction in any medium, provided the original author and source are credited.
Categories: Internal Medicine, Oncology

Keywords: tki, egfr, sclc, nsclc, osimertinib

\section{Introduction}

Lung cancer is the leading cause of cancer-related mortality in the world [1]. Lung cancers are broadly classified into small cell lung cancer (SCLC) and non-small cell lung cancer (NSCLC) based on microscopic features of the tumor cells. Epidermal growth factor receptor (EGFR) mutations are present in one-third of the patients with NSCLC, with a higher prevalence in females and non-smokers and around two-third of the patients having adenocarcinoma on histology [2]. EGFR tyrosine kinase inhibitors (TKI) are the first-line of therapy for metastatic EGFR-receptor-positive NSCLC due to better clinical outcome and lesser toxicity profile as compared to standard chemotherapy [3-5].

SCLC is a neuroendocrine tumor that accounts for less than $15 \%$ cases of lung cancer [6]. SCLC has been shown to respond to platinum-based chemotherapy and immunotherapy. Often, a combination therapy has been the mainstay of treatment. EGFR mutations are rarely reported with SCLC in literature [7-9]. We present a case of a 63-year-old female with SCLC associated with EGFR mutation that was treated with the third-generation EGFR-TKI, Osimertinib.

This article has been submitted as an abstract at https://afmr.org/Eastern/2021/24.cgi.

\section{Case Presentation}

A 63-year-old woman, never smoker, presented to the hospital with a complaint of cough and blood in sputum for one month. Cachexia was noted on physical examination. Initial CT chest showed two rightlower lobe lung nodules, with the largest nodule measuring $2.1 \mathrm{~cm}$, as well as pleural-based nodule and enlarged mediastinal lymph nodes (Figure 1). 


\section{Cureus}

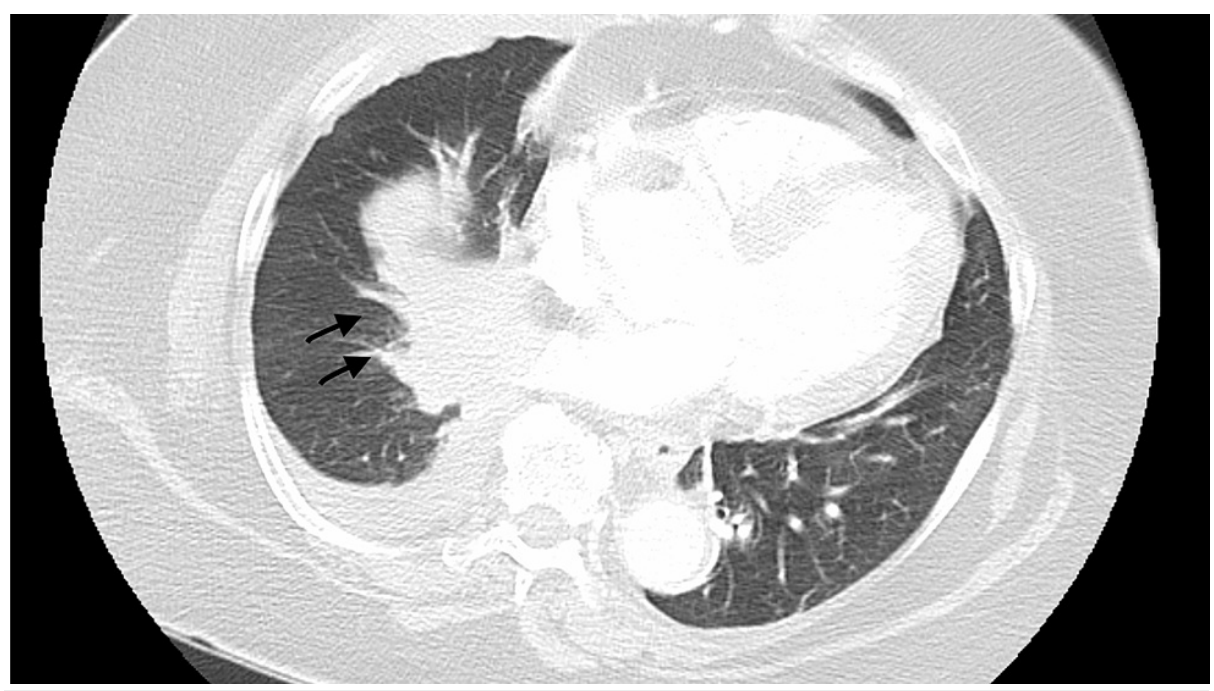

FIGURE 1: Initial CT chest with contrast showed hilar involvement of mass.

CT abdomen pelvis revealed a pancreatic mass. MRI brain showed several nodular densities suggestive of metastatic disease despite absence of symptoms (Figures $2 A, 2 B$ ).

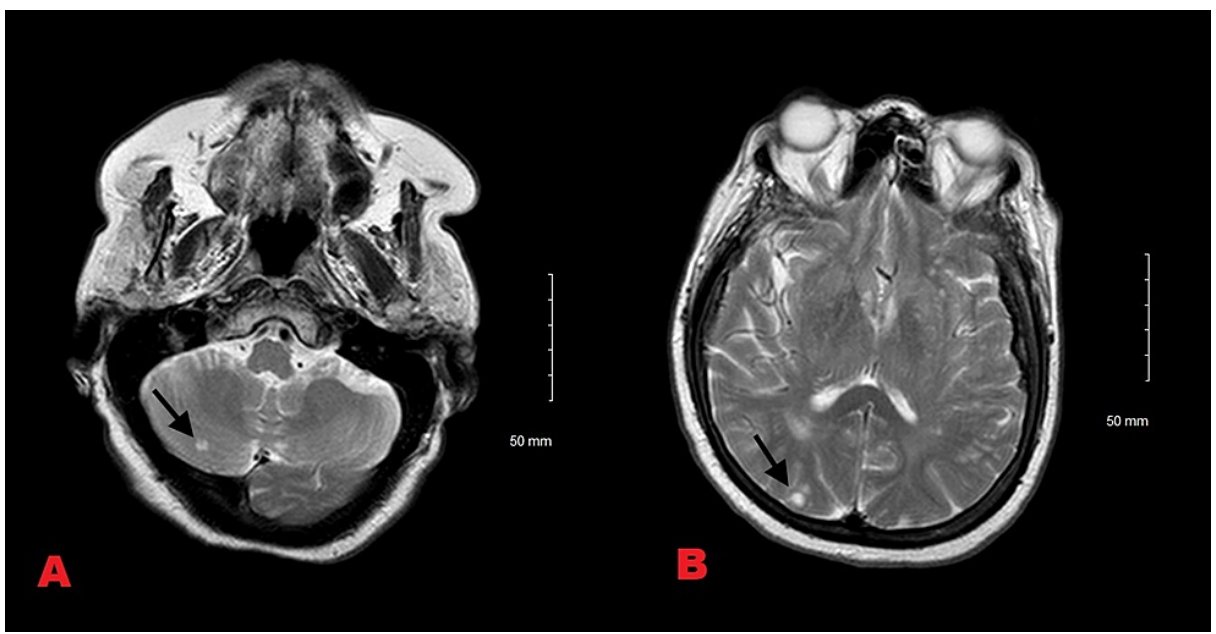

FIGURE 2: A. MRI brain showing a nodule in the right cerebellar hemisphere (arrow). B. Showing another nodule in the right occipital lobe.

The patient eventually underwent a bronchoscopy, where endobronchial biopsies were obtained from the right-lower lobe lesions. Bronchial brushings were positive for malignant cells. The initial biopsy results revealed clusters of atypical cells with severe crushing effects consistent with SCLS.

Immunohistochemistry revealed SCLC with EGFR positive for Exon $212573 \mathrm{~T}>\mathrm{G}$ L858R mutation as well as a high proliferative index (ki-67, 80\%), and positive TTF-1 and synaptophysin. Tumor cells were negative for chromogranin and p63. The patient was classified as a Stage IV SCLC. Given the mildly symptomatic disease, the patient was started on targeted therapy with osimertinib with close monitoring of the pulmonary status. The patient completed about two months of osimertinib when her clinical status worsened and she required hospitalization after developing pneumonia and new pleural effusion. Follow-up CT chest revealed new mediastinal lymph nodes with pneumonia and worsening atelectasis (Figure 3). 


\section{Cureus}

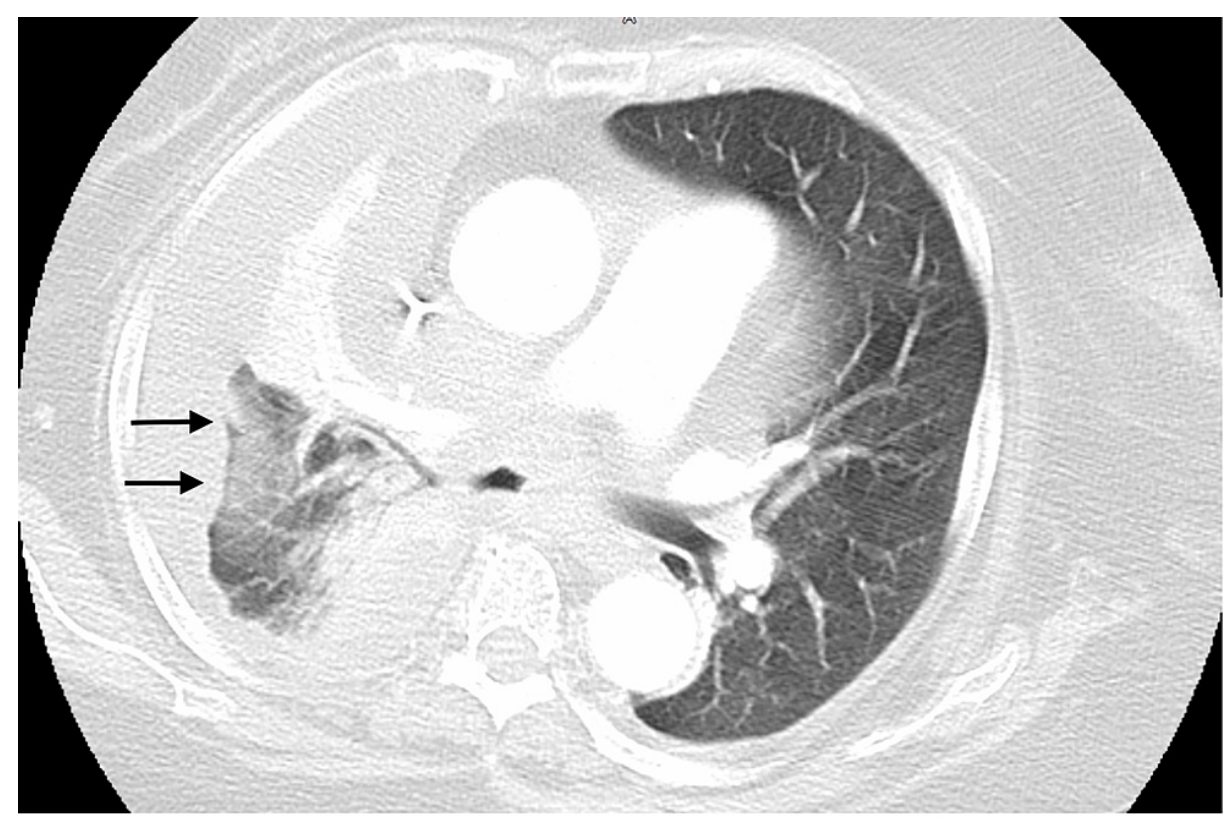

FIGURE 3: Follow up CT chest three months later showed compressive atelectasis of the right lung (arrows).

The patient was subsequently treated for pneumonia with antibiotics without any improvement in symptoms. A decision was made to stop TKI therapy and start palliative chemotherapy with carboplatin and etoposide. The patient's medical condition deteriorated rapidly and she opted for home hospice care.

\section{Discussion}

The standard of care treatment for extensive stage (ES) SCLC is a combination of anti-PD 1 monoclonal antibody with etoposide-platinum chemotherapy. Alemtuzumab in combination with etoposide and carboplatin for patients with ES-SCLC showed an overall survival of 12.3 months vs 10.3 in months in patients with etoposide and carboplatin alone [10]. Similarly, a randomized clinical trial showed an overall survival of 13 months in durvalumab plus platinum-etoposide group versus 10.3 months in the etoposideplatinum alone group [11]. Although SCLC and NSCLC are histologically distinct entities with completely different treatment options, a study of 177 cases of SCLC has shown that 17 cases had components of NSCLC on histology and seven of these patients received a diagnosis of NSCLC initially [12]. Another common cause of concern in NSCLC is acquired mutations to TKI by histological conversion to SCLC. One study reported that out of 37 patients who developed resistance to TKI, five (14\%) had histological conversion to SCLC [13]. Okamato et al. reported a case of exon 19 deletion positive EGFR mutation in a patient with metastatic SCLC who received treatment with TKI gefitinib and showed regression of both primary lung lesion and metastatic liver lesion [7].

The third-generation TKI, osimertinib, is approved as the first-line therapy for metastatic NSCLC with EGFR exon 19 deletion or exon 21 L858R mutation. Treatment with osimertinib showed a median progression-free survival of 18.9 months compared to 10.2 months when treated with first-generation EGFR TKIs (gefitinib or erlotinib) [14]. Our patient had metastatic SCLC with EGFR L858R mutation and a decision was made to attempt osimertinib as an initial therapy after the discussion of benefits and risks of standard platinumbased chemotherapy and immunotherapy.

In our patient, treatment with osimertinib did not show any meaningful improvement and the disease continued to progress. However, in our patient, TKI was not used in combination with cytotoxic chemotherapy. Studies have shown that after NSCLC transformation to SCLC, the SCLC responds to standard chemotherapy with platinum and etoposide [15]. The emergence of EGFR mutation in SCLC is relatively recent and studies have shown conflicting results of the efficacy of TKIs. This underscores the importance of further studies to see if TKIs, either alone or in combination with standard chemotherapy, show any better outcomes than the standard of care.

\section{Conclusions}

TKI shows a good clinical response and is approved as the first-line therapy for metastatic EGFR mutationpositive NSCLC. The detection of EGFR mutation in SCLC underlines the importance of further studies to evaluate the efficacy and safety of TKIs, alone or in combination with standard of care, for the treatment SCLC. 


\section{Additional Information \\ Disclosures}

Human subjects: Consent was obtained or waived by all participants in this study. Conflicts of interest: In compliance with the ICMJE uniform disclosure form, all authors declare the following: Payment/services info: All authors have declared that no financial support was received from any organization for the submitted work. Financial relationships: All authors have declared that they have no financial relationships at present or within the previous three years with any organizations that might have an interest in the submitted work. Other relationships: All authors have declared that there are no other relationships or activities that could appear to have influenced the submitted work.

\section{References}

1. Torre LA, Bray F, Siegel RL, Ferlay J, Lortet-Tieulent J, Jemal A: Global cancer statistics, 2012. CA Cancer J Clin. 2015, 65:87-108. 10.3322/caac.21262

2. Zhang YL, Yuan JQ, Wang KF, et al.: The prevalence of EGFR mutation in patients with non-small cell lung cancer: a systematic review and meta-analysis. Oncotarget. 2016, 7:78985-93. 10.18632/oncotarget.12587

3. Mitsudomi T, Morita S, Yatabe Y, et al.: Gefitinib versus cisplatin plus docetaxel in patients with non-smallcell lung cancer harbouring mutations of the epidermal growth factor receptor (WJTOG3405): an open label, randomised phase 3 trial. Lancet Oncol. 2010, 11:121-128. 10.1016/S1470-2045(09)70364-X

4. First-line erlotinib versus gemcitabine/cisplatin in patients with advanced EGFR mutation-positive nonsmall-cell lung cancer: analyses from the phase III, randomized, open-label, ENSURE study 10.1093/annonc/mdv270. https://www.annalsofoncology.org/article/S0923-7534(19)31770-3/fulltext.

5. Chen G, Feng J, Zhou C, et al.: Quality of life (QoL) analyses from OPTIMAL (CTONG-0802), a phase III, randomised, open-label study of first-line erlotinib versus chemotherapy in patients with advanced EGFR mutation-positive non-small-cell lung cancer (NSCLC). Ann Oncol. 2013, 24:1615-22.

10.1093/annonc/mdt012

6. Govindan R, Page N, Morgensztern D, et al.: Changing epidemiology of small-cell lung cancer in the United States over the last 30 years: analysis of the surveillance, epidemiologic, and end results database. J Clin Oncol. 2006, 24:4539-44. 10.1200/JCO.2005.04.4859

7. Okamoto I, Araki J, Suto R, Shimada M, Nakagawa K, Fukuoka M: EGFR mutation in gefitinib-responsive small-cell lung cancer. Ann Oncol. 2006, 17:1028-1029. 10.1093/annonc/mdj114

8. Zakowski MF, Ladanyi M, Kris MG: EGFR mutations in small-cell lung cancers in patients who have never smoked. N Engl J Med. 2006, 355:213-5. 10.1056/NEJMc053610

9. Oser MG, Niederst MJ, Sequist LV, Engelman JA: Transformation from non-small-cell lung cancer to smallcell lung cancer: molecular drivers and cells of origin. Lancet Oncol. 2015, 16:e165-72. 10.1016/S14702045(14)71180-5

10. Horn L, Mansfield AS, Szczęsna A, et al.: First-line atezolizumab plus chemotherapy in extensive-stage small-cell lung cancer. N Engl J Med. 2018, 379:2220-9. 10.1056/NEJMoa1809064

11. Paz-Ares L, Dvorkin M, Chen Y, et al.: Durvalumab plus platinum-etoposide versus platinum-etoposide in first-line treatment of extensive-stage small-cell lung cancer (CASPIAN): a randomised, controlled, openlabel, phase 3 trial. Lancet. 2019, 394:1929-39. 10.1016/S0140-6736(19)32222-6

12. Adelstein DJ, Tomashefski JF Jr, Snow NJ, Horrigan TP, Hines JD: Mixed small cell and non-small cell lung cancer. Chest. 1986, 89:699-704. 10.1378/chest.89.5.699

13. Sequist LV, Waltman BA, Dias-Santagata D, et al.: Genotypic and histological evolution of lung cancers acquiring resistance to EGFR inhibitors. Sci Transl Med. 2011, 3:75ra26. 10.1126/scitranslmed.3002003

14. Soria JC, Ohe Y, Vansteenkiste J, et al.: Osimertinib in untreated EGFR-mutated advanced non-small-cell lung cancer. N Engl J Med. 2018, 378:113-25. 10.1056/NEJMoa1713137

15. Marcoux N, Gettinger SN, O'Kane G, et al.: EGFR-mutant adenocarcinomas that transform to small-cell lung cancer and other neuroendocrine carcinomas: clinical outcomes. J Clin Oncol. 2019, 37:278-85. 10.1200/JCO.18.01585 